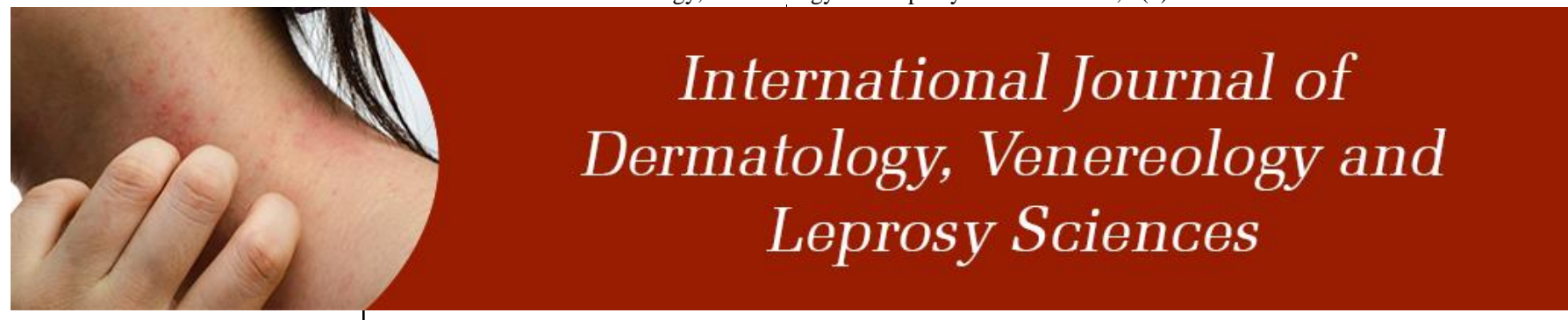

E-ISSN: 2664-942X P-ISSN: 2664-9411 www.dermatologypaper.com/ Derma 2018; 1(1): 14-16 Received: 15-11-2017 Accepted: 17-12-2017

Dr. Rahul Roy Department of Dermatology, R.G. Kar Medical College and Hospital, Kolkata, West Bengal, India
Corresponding Author: Dr. Rahul Roy

Department of Dermatology, R.G. Kar Medical College and Hospital, Kolkata, West Bengal, India

\section{To assess hyperpigmentation in patients with vitamin B12 deficiency: A clinical study}

\section{Dr. Rahul Roy}

DOI: https://doi.org/10.33545/26649411.2018.v1.i1a.5

\begin{abstract}
Background: Vitamin B12 deficiency has been a known clinical entity for long. The present study was conducted to assess hyper-pigmentation in patients with vitamin B12 deficiency.

Materials \& Methods: The present study was conducted on 32 patients of both genders visited to the department with complaint of hyper-pigmentation. History of diet, jaundice and skin changes was recorded. All patients were subjected to hematological evaluation.

Results: 14 were vegetarian and 18 were non- vegetarian, 32 had skin changes, 4 had jaundice. The difference was significant $(P<0.05)$. Mean hemoglobin was $6.12 \mathrm{gm} / \mathrm{dl}$, WBC was $4.36 \mathrm{x} 103 / \mathrm{mm} 3$, platelets was $1.28 \times 106 / \mathrm{mm} 3$, RBC was $1.98 \times 105 / \mathrm{mm} 3$, MCV was $107.2 \mathrm{fl}$, MCH was $32.4 \mathrm{pg}$, vitamin B12 was $124.2 \mathrm{pg} / \mathrm{ml}$ and folic acid was $7.8 \mathrm{ng} / \mathrm{ml}$.

Conclusion: There was hyper-pigmentation of skin in which with vitamin B 12 deficiency. Thus patients should be carefully evaluated.
\end{abstract}

Keywords: Hyper-pigmentation, Skin changes, Vitamin B12

\section{Introduction}

Vitamin B12 (cobalamin) deficiency has been a known clinical entity for long. Megaloblastic anemia results from abnormal maturation of hematopoietic cells due to faulty DNA synthesis. Two vitamins, cobalamin (vitamin B12) and folic acid are essential for DNA biosynthesis. Deficiency of either of these vitamins results in asynchrony in the maturation of the nucleus and cytoplasm of rapidly regenerating cells. In the hematopoietic system, this asynchrony results in abnormal nuclear maturation with normal cytoplasmic maturation, apoptosis, ineffective erythropoiesis, intramedullary haemolysis, pancytopenia and typical morphological abnormalities in the blood and marrow cells. The occurrence of hyperpigmentation in vit B12 deficiency is not very common.

The true prevalence of vitamin B12 deficiency in the general population is unknown. The incidence, however, appears to increase with age. In one study, percent of adults older than 65 years had laboratory evidence of vitamin B12 deficiency. The nearly ubiquitous use of gastric acid-blocking agents, which can lead to decreased vitamin B12 levels, may have an underappreciated role in the development of vitamin B12 deficiency.

In addition to hematologic and neuropsychiatric manifestations, vitamin B12 deficiency may exert indirect cardiovascular effects. Similar to folic acid deficiency, vitamin B12 deficiency produces hyperhomocysteinemia, which is an independent risk factor for atherosclerotic disease. Although the role of folic acid supplementation in reducing homocysteine levels as a method for preventing coronary artery disease and stroke continues to be a subject of great interest, there has been little emphasis on the potential role of vitamin B12 deficiency as a contributing factor in the development of cardiovascular disease. The present study was conducted to assess hyperpigmentation in patients with vitamin B12 deficiency.

\section{Materials \& Methods}

The present study was conducted in the department of Dermatology. It comprised of 32 patients of both genders visited to the department with complaint of hyperpigmentation. Patients with raised MCV (>100 fl), bicytopenia or pancytopenia were included. The study was approved from institutional ethical committee. All participants were informed regarding the study and written consent was obtained.

Information such as name, age, gender etc. was recorded. History of diet, jaundice and skin changes was recorded. All patients were subjected to hematological evaluation. Results thus. 
obtained were subjected to statistical analysis. $\mathrm{P}$ value less than 0.05 was considered significant.

\section{Results}

Table I: Distribution of participants

\begin{tabular}{|c|c|c|}
\hline & Total- 32 & \\
\hline Gender & Males & Females \\
\hline Number & 12 & 20 \\
\hline
\end{tabular}

Table I shows that out of 32 patients, males were 12 and females were 20 .
Table II: Demographic Profile in patients

\begin{tabular}{|c|c|c|}
\hline Characteristics & Value & \multirow{2}{*}{ P value } \\
\hline Diet & & \multirow{2}{*}{0.98} \\
\hline Vegetarian & 14 & \\
\hline Non- vegetarian & 18 & \\
\hline Skin changes & & \multirow{2}{*}{0.01} \\
\hline Yes & 32 & \\
\hline No & 0 & \multirow{2}{*}{0.02} \\
\hline Jaundice & 4 & \\
\hline Yes & 28 & \\
\hline No & &
\end{tabular}

Table II shows that 14 were vegetarian and 18 were nonvegetarian, 32 had skin changes, 4 had jaundice. The difference was significant $(P<0.05)$.

Table III: Hematological profile of patients

\begin{tabular}{|c|c|}
\hline Characteristics & Mean value \\
\hline Hemoglobin $(\mathrm{gm} / \mathrm{dl})$ & 6.12 \\
\hline WBC $\left(\times 10^{3} / \mathrm{mm}^{3}\right)$ & 4.36 \\
\hline Platelets $\left(\times 10^{6} / \mathrm{mm}^{3}\right)$ & 1.28 \\
\hline $\mathrm{RBC}\left(\mathrm{x} 10^{5} / \mathrm{mm}^{3}\right)$ & 1.98 \\
\hline $\mathrm{MCV}(\mathrm{fl})$ & 107.2 \\
\hline $\mathrm{MCH}(\mathrm{pg})$ & 32.4 \\
\hline Vitamin B12 $(\mathrm{pg} / \mathrm{ml})$ & 124.2 \\
\hline Folic acid $(\mathrm{ng} / \mathrm{ml})$ & 7.8 \\
\hline
\end{tabular}

Table III, graph I shows that mean hemoglobin was $6.12 \mathrm{gm} / \mathrm{dl}$, WBC was $4.36 \times 10^{3} / \mathrm{mm}^{3}$, platelets was 1.28 $\mathrm{x} 10^{6} / \mathrm{mm}^{3}$, RBC was $1.98 \times 10^{5} / \mathrm{mm} 3, \mathrm{MCV}$ was $107.2 \mathrm{fl}$, MCH was $32.4 \mathrm{pg}$, vitamin B12 was $124.2 \mathrm{pg} / \mathrm{ml}$ and folic acid was $7.8 \mathrm{ng} / \mathrm{ml}$.

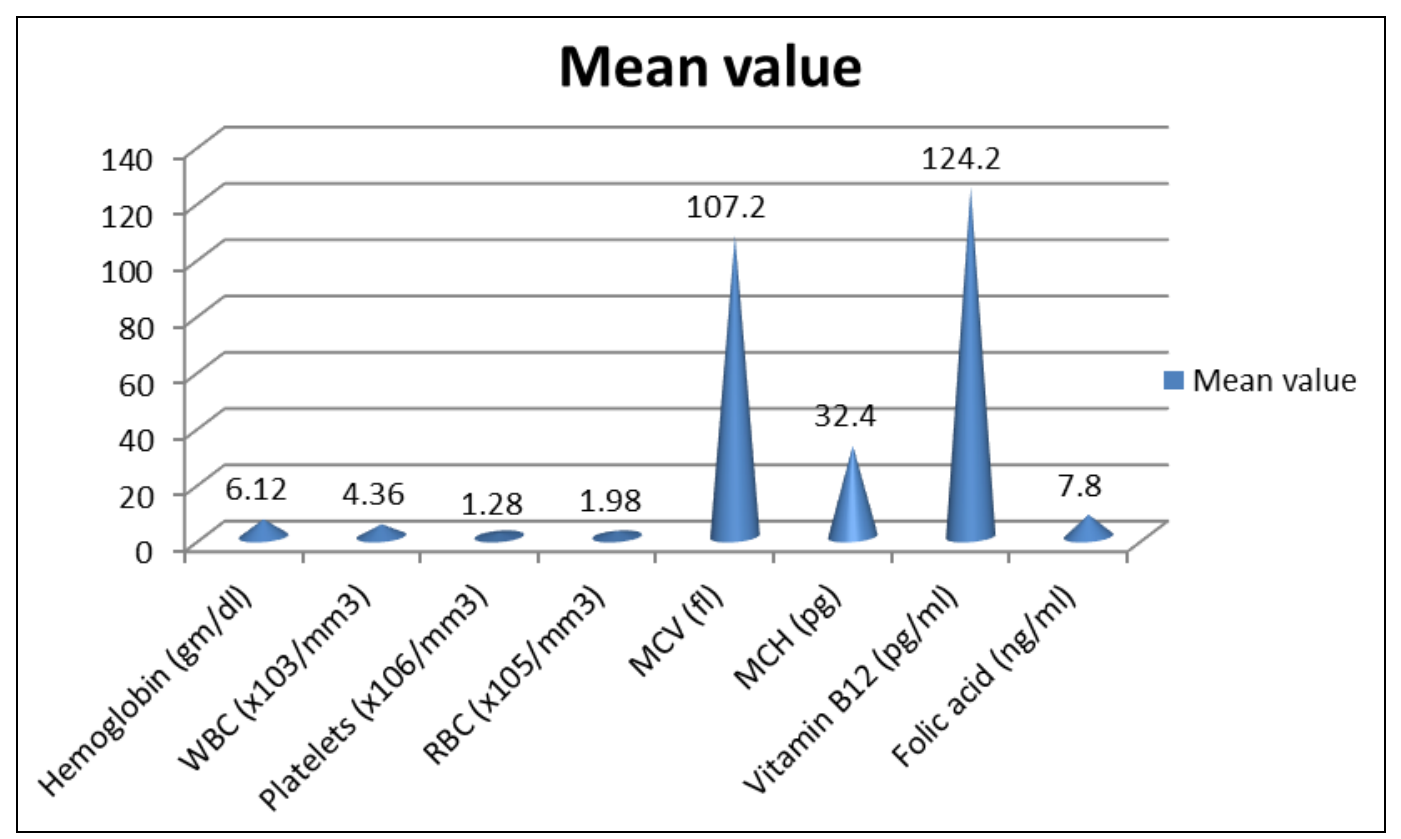

Graph I: Hematological profile of patients

\section{Discussion}

The diagnosis of vitamin B12 deficiency has traditionally been based on low serum vitamin B12 levels, usually less than 200 pg per, along with clinical evidence of disease. However, studies indicate that older patients tend to present with neuropsychiatric disease in the absence of hematologic findings. Furthermore, measurements of metabolites such as methylmalonic acid and homocysteine have been shown to be more sensitive in the diagnosis of vitamin B12 deficiency than measurement of serum B12 levels alone. The average Indian vegetarian diet is deficient in cobalamin and this must be noted when considering the results of the earlier studies from north and south India because of the large vegetarian diet population. The present study was conducted to assess hyperpigmentation in patients with vitamin B12 deficiency.

In present study, out of 32 patients, males were 12 and females were 20. 14 were vegetarian and 18 were nonvegetarian, 32 had skin changes, 4 had jaundice. Kannan et al. ${ }^{\text {[9] }}$ conducted a study to know the clinical profile of vitamin B12 deficiency in population and if there is any relationship between dermatologic manifestations with vitamin B12 deficiency. Twenty five patients were tested for vitamin B12 deficiency. Of them 19 patients were found to be having vitamin $\mathrm{B} 12$ deficiency.

We found that mean hemoglobin was $6.12 \mathrm{gm} / \mathrm{dl}$, WBC was 
$4.36 \times 10^{3} / \mathrm{mm}^{3}$, platelets was $1.28 \times 10^{6} / \mathrm{mm}^{3}$, RBC was 1.98 $\mathrm{x} 10^{5} / \mathrm{mm} 3$, MCV was $107.2 \mathrm{fl}, \mathrm{MCH}$ was $32.4 \mathrm{pg}$, vitamin B12 was $124.2 \mathrm{pg} / \mathrm{ml}$ and folic acid was $7.8 \mathrm{ng} / \mathrm{ml}$. Sen et al. ${ }^{[10]}$ found that twenty-one of 25 cases $(84 \%)$ had MA, while MA without hyperpigmentation occurred only in 12 of remainder 173 cases. Knuckle pad hyperpigmentation (KP) was noted in $16(64 \%)$ cases; whereas 9 (36\%) had diffuse brownish black discoloration (DP) of the palms and /or soles. Eighteen of 25 (72\%) cases had pancytopenia (13 with KP) and 7 of 25 (28\%) had bicytopenia. In addition, five cases $(20 \%)$ presented with pyrexia. Of the 17 cases where data available, eleven were B12 deficient, while 4 had pure folate deficiency and remainder 2 had combined $\mathrm{B}_{12}$ and folate deficiency. Compared to those with diffuse pigmentation; KP group had lower $\mathrm{Hb}(69.6 \pm 24.2$ vs. 86.3 $\pm 33.9 \mathrm{~g} / \mathrm{L})$, higher MCV $(106.1 \pm 2.6$ vs. $99.2 \pm 7.6 \mathrm{fL})$, lower platelet count $\left(50.9 \pm 29.3\right.$ vs. $\left.69.6 \pm 36.5 \times 10^{9} / \mathrm{L}\right)$, and lower median $\mathrm{B}_{12}$ [100.0 (30.0 - 822.0) vs. 316.0 (142.0 1617.3) $\mathrm{pg} / \mathrm{ml}$. In six cases where follow-up data were available, there was a significant reversal of hyperpigmentation at 12 weeks following parenteral cobalamin therapy. In all five cases with pyrexia, fever subsided after 24 to 72 hours following administration of parenteral cobalamin therapy.

Baker and colleagues ${ }^{[11]}$ described characteristic reversible brownish-black pigmentation over dorsal aspect of interphalangeal joints of hands and feet (KP) in a large series of 21 South Indian subjects with MA (15 adults, 6 infants/children). Malabsorption was the commonest cause of B12 deficiency in that series; and the mean serum B12 level among cases was very low $(49 \mathrm{pg} / \mathrm{ml})$ by using microbiological assay method. A recent prospective study recruited 57 pediatric subjects (mean age; $12.75 \pm 4.75$ months) of which $49(86 \%)$ were exclusively breastfed. A higher proportion $(63 \%)$ of cases had a severe B12 deficiency $(<100 \mathrm{pg} / \mathrm{ml})$; and 44 of 57 mothers were also B12 deficient ( $<200 \mathrm{pg} / \mathrm{ml})$. Forty-nine of $57(86 \%)$ babies had CP and $40(70 \%)$ had atrophic glossitis. On serial follow-up at the end of 1 week, 4 weeks, and 12 weeks, there was a dramatic improvement in mucocutaneous changes at 12 weeks following parenteral cobalamin therapy [12].

\section{Conclusion}

Authors found that there was hyperpigmentation of skin in which with vitamin B 12 deficiency. Thus patients should be carefully evaluated.

\section{References}

1. Carmel R. Efficacy and safety of fortification and supplementation with vitamin B12: Biochemical and physiological effects. Food Nutr Bull. 2008; 29(2):17787.

2. Bhatia P, Kulkarni JD, Pai SA. Vitamin B12 deficiency in India: Mean corpuscular volume is an unreliable screening parameter. Natl Med J India. 2012; 25:336-8.

3. Sharma D, Sharma P. Analysis of Lymphocytes Count in Premenopausal Women with Iron Deficiency Anemia. J Adv Med Dent Sci. Res. 2018; 6(10):124127.

4. Premkumar M, Gupta N, Singh T, Velpandian T. Cobalamin and folic acid status in relation to the etiopathogenesis of pancytopenia in adults in a tertiary care centre in North India. Anemia. 2012; 2012:707402.
5. Khanduri U, Sharma A. Megaloblastic anemia: Prevalence and causative factors. Natl Med J India. 2007; 20:172-5.

6. Oh RC, Brown DL. Vitamin B12 deficiency. Am Fam Physician. 2003; 67:979-86.

7. Aaron S, Kumar S, Vijayan J, Jacob J, Alexander M, Gnanamuthu C. Clinical and laboratory features and response to treatment in patients presenting with vitamin B12 deficiency-related neurological syndromes. Neurol India. 2005; 53:55-8.

8. Antony AC. Vegetarianism and vitamin B 12 (cobalamin) deficiency. Am J Clin Nutr. 2003; 78:3-6.

9. Kannan R, Ng MJ. Cutaneous lesions and vitamin B12 deficiency: An often forgotten link. Can Fam Physician. 2008; 54:529-32.

10. Sen K, Sinhamahapatra P, Lalhmachhuana J, Ray S. A study of clinical profile of vitamin B12 deficiency with special reference to dermatologic manifestations in a Tertiary Care Hospital in sub-Himalayan Bengal. Indian J Dermatol. 2015; 60:419.

11. Baker SJ, Ignatius $M$, Johnson $S$, Vaish SK. Hyperpigmentation of skin. A sign of vitamin B12 deficiency. Br Med J. 1963; 1:1713-5.

12. Baker SJ, Ignatius $M$, Johnson $S$, Vaish SK. Pigmentation and vitamin B12 deficiency. Br Med J. $1963 ; 2: 1205$. 